\title{
Effects of training period on haemorheological variables in regularly trained footballers
}

\author{
Y Karakoc, H Duzova, A Polat, M H Emre, I Arabaci
}

Br J Sports Med 2005;39:e4 (http://www.bjsportmed.com/cgi/content/full/39/2/e4). doi: 10.1136/bjsm.2003.010637

See end of article for authors' affiliations

.....................

Correspondence to: Dr Karakoc, Department of Physiology, Faculty of Medicine, Inonu University, Malatya 44280, Turkey; ykarakoc@inonu.edu.tr

Accepted 9 March 2004
Objective: To investigate the effects of one football training period on haemorheological variables in regularly trained footballers.

Method: Ten subjects were randomly selected from the reserve team of a football club in the Turkish Premier League. During the last week of the football season, one day before a standard training session and two days after the previous league match, venous blood samples were taken (pre-exercise). After 90 minutes of standard training, further blood samples were taken (post-exercise). Blood lactate, blood viscosity, plasma fibrinogen, blood clotting time, acid-base variables, and plasma $\mathrm{Na}^{+}, \mathrm{K}^{+}$, and $\mathrm{Ca}^{2+}$ were determined.

Results: Haemoglobin, packed cell volume, and mean corpuscular volume were all significantly decreased, whereas white blood cells and platelets were both increased after training. Blood viscosity decreased but the reduction was not significant. Blood lactate, plasma glucose, and $\mathrm{Na}^{+}$content were significantly increased, but standard bicarbonate, actual bicarbonate, and $\mathrm{Ca}^{2+}$ were significantly decreased. Blood clotting time had shortened significantly after training. Blood viscosity was inversely correlated with plasma glucose concentration $(r=-0.48$ and $p=0.032)$.

Conclusions: The results show that blood viscosity tends to decrease as the result of this type of training. This is due to a reduction in packed cell volume and mean corpuscular volume. The increased blood lactate does not have an adverse effect on the blood viscosity of these subjects because protective mechanisms develop with regular training throughout the season.
$\mathrm{T}$ he haemorheological effect of exercise is a triphasic phenomenon, including short, middle, and long term effects. In the short term, hyperviscosity occurs mostly due to fluid shifts and alterations in erythrocyte rigidity and aggregability. Middle term effects include reversal of the acute effects through plasma volume expansion, which lowers both plasma viscosity and packed cell volume. Long term effects are further improvement in blood fluidity, in parallel with classic training induced hormonal and metabolic alterations. ${ }^{1}$

The effects of exercise and training have been extensively investigated in humans using different experimental protocols. ${ }^{2-6}$ It has been shown that whole blood viscosity and plasma viscosity increase in response to a variety of exercise protocols. $^{7}$

In this study, we aimed to investigate the effects of one training period of football on haemorheological variables in regularly trained footballers. Our hypothesis was that, at the end of a football season, the raised blood lactate concentrations after training for 90 minutes would affect haemorheological variables, and hyperviscosity might occur. On the other hand, training might cause metabolic acidosis in the blood which, in turn, might affect red blood cell and whole blood rheology.

\section{MATERIALS AND METHODS}

Ten subjects were randomly selected from the reserve team of a football club in the Turkish Premier League. They were asked about their performance and any health problems. Physical characteristics such as age and height were recorded. Written informed consent was obtained from all the subjects. During the last week of the football season, one day before a standard training session and two days after the previous league match, venous blood samples were taken from the right antecubital vein (pre-exercise). After 90 minutes of standard training, further blood samples were taken from the left antecubital vein within two minutes (post-exercise). The samples were immediately transferred to analytical tubes containing different types of anticoagulant. Preexercise and post-exercise blood samples were transported separately to the laboratory in a cooled container as soon as possible.

Blood lactate concentrations were analysed as soon as blood samples were taken by a lactate strip reader device (Arkray, Kyoto, Japan). Red blood cell, haemoglobin, packed cell volume, mean corpuscular volume, platelets, and white blood cells were determined with an automatic cell analyser (Beckman Coulter, Fullerton, California, USA). Measurements of plasma fibrinogen and blood clotting time were performed using a coagulometer (Dade Behring, Marburg, Germany). Whole blood viscosities were determined with a rotational viscometer (modified NDJ-1, Ceti, Liege, Belgium) with the rotor numbered zero at $60 \mathrm{rpm}$ at $37^{\circ} \mathrm{C}$. Acid-base variables of venous blood and $\mathrm{Na}^{+}, \mathrm{K}^{+}$, and $\mathrm{Ca}^{2+}$ were analysed by a blood gas analyser system (Stat-Profile-Ultra; Novbio Medical, Waltham, Massachusetts, USA).

Statistical analyses were performed by paired $t$ test because of the homogeneous variance, and correlations among the variables were investigated.

\section{RESULTS}

The mean (SD) age of the subjects was 18.4 (1.3) years, and their body mass indexes ranged from 18.9 to 23.0 (mean 21.7). All subjects were in good health and had had no noteworthy health or traumatic problems during the football season. Table 1 shows pre-exercise and post-exercise haematological variables and some haematological indices. Haemoglobin, packed cell volume, and mean corpuscular volume were all significantly decreased whereas white blood cells and platelets were both increased after training. 
Table 1 Haematological variables before and after exercise

\begin{tabular}{llll}
\hline & $\begin{array}{l}\text { Pre-exercise } \\
(\mathbf{n}=10)\end{array}$ & $\begin{array}{l}\text { Post-exercise } \\
(\mathbf{n}=10)\end{array}$ & p Value \\
\hline RBCs $\left(\times 10^{6} / \mathrm{mm}^{3}\right)$ & $5.12(0.27)$ & $5.06(0.28)$ & 0.156 \\
$\mathrm{Hb}(\mathrm{g} / \mathrm{l})$ & $154(8.9)$ & $150(9.6)$ & 0.012 \\
$\mathrm{PCV}$ & $0.44(0.02)$ & $0.42(0.03)$ & 0.006 \\
$\mathrm{MCV}\left(\mu \mathrm{m}^{3}\right)$ & $85.7(3.49)$ & $83.1(3.58)$ & 0.005 \\
$\mathrm{RDW}(\%)$ & $12.6(0.73)$ & $12.6(0.77)$ & 0.899 \\
$\mathrm{PLTs}\left(\times 10^{3} / \mathrm{mm}^{3}\right)$ & $262(34.6)$ & $356(56.3)$ & 0.000 \\
$\mathrm{WBCs}\left(\times 10^{3} / \mathrm{mm}^{3}\right)$ & $8.5(1.83)$ & $12.4(1.75)$ & 0.000 \\
\hline
\end{tabular}

Values are mean (SD).

$\mathrm{RBC}$, Red blood cell; Hb, haemoglobin; PCV, packed cell volume; MCV, mean corpuscular volume; RDW, red cell distribution; PLT, platelet; WBC, white blood cell.

Table 2 shows whole blood viscosity, blood lactate, and other variables before and after exercise. Blood viscosity appeared to decrease after training, but the difference was not significant. Blood lactate, plasma glucose, and $\mathrm{Na}^{+}$were significantly increased, whereas plasma standard bicarbonate, actual bicarbonate, and $\mathrm{Ca}^{2+}$ concentrations were significantly decreased. We found no significant change in plasma fibrinogen. However, the blood clotting time had shortened significantly after training. It is noteworthy that blood viscosity was inversely correlated with plasma glucose concentration $(r=-0.48, \mathrm{p}=0.032)$.

\section{DISCUSSION}

Most metabolic and hormonal alterations play a role in exercise induced haemorheological changes. Of these, blood lactate appears to have opposite effects according to the training status, as it generally impairs erythrocyte fluidity. Body composition as well as the major hormonal regulating systems are both considerably modified by training, and these modifications are correlated with haemorheology. ${ }^{1}$

In our study, blood lactate concentrations were significantly increased after training. In fact, they were are above the physiological range in these subjects. Contrary to our hypothesis, venous acid-base balance favoured compensated respiratory alkalosis rather than metabolic acidosis.

We were surprised at the decrease in blood viscosity after training. This paralleled decreases in red blood cell count, packed cell volume, and mean corpuscular volume of red blood cells. These changes appear to be in response to the increase in shear rate that occurs at the end of training as well as haemodilution, which is a middle term effect of exercise. Although the increases in $\mathrm{Na}^{+}$content of plasma supports the fluid shift from the intracellular space to the plasma, the increases in white blood cell and platelet count and decreases in blood clotting time may be attributed to the high shear rate in the systemic circulation of these subjects at the end of a single training period. Blood was taken within two minutes of the end of training, before the recovery of disturbed processes in the blood. Volume depletion of red blood cells may be a protective measure to reduce blood viscosity during fluid shift from the plasma to the extravascular space. Microcirculatory studies have shown a significant increase in basal perfusion after exercise compared with the resting state. ${ }^{8}$

Increased white blood cell counts after training have been reported in other studies. Perez et al showed a significant increase in white blood cell number after both laboratory and field exercise protocols in children. In another study, ${ }^{10}$ white blood cell and neutrophil number had significantly increased at the end of a football training session compared with baseline values. Increased white blood cell number in
Table 2 Blood viscosity, blood lactate, and other variables before and after training

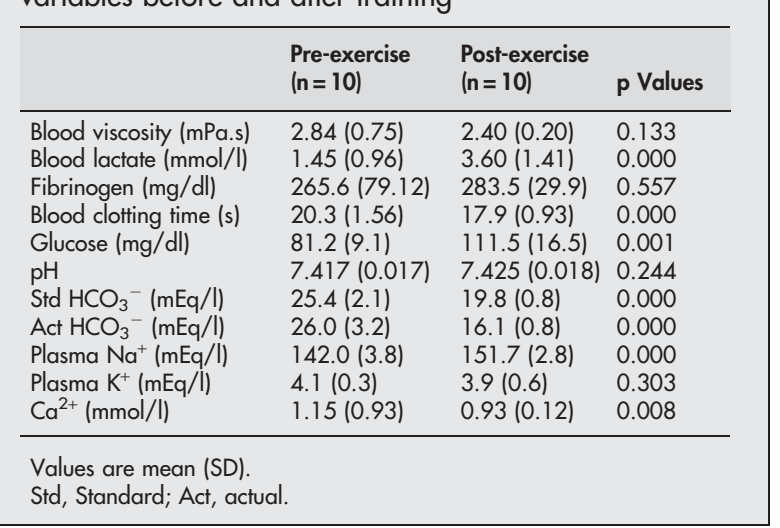

response to exercise in these subjects may be attributed to a demargination process caused by exercise or adrenaline (epinephrine) administration. Normally about half of the blood leucocytes are in a marginal pool-that is, loosely adherent to the vascular endothelium or trapped in the microcirculation. With exercise or adrenaline administration, these cells are released into the circulating pool and the leucocyte count rises, a process called demargination. ${ }^{11}$

In this study, the increase in plasma glucose concentration after training may be due to raised blood lactate concentration. We also found a positive correlation between blood lactate and plasma glucose concentrations $(r=$ $0.558, \mathrm{p}=0.010)$. Excess lactic acid accumulation inhibits further ATP production. Although the excess lactic acid causes fatigue during exercise, this inhibitory effect is a protective response, as excess acidity can lead to cell death. After exercise, excess lactate is converted back into glucose in the liver. This newly made glucose can then be used to resynthesise the glycogen depleted during exercise. The rate of lactic acid removal is faster active compared with passive recovery. ${ }^{12}$

The decrease in plasma $\mathrm{Ca}^{2+}$ after training is similar to the results of previous studies. This finding may be related to the effects of the training conditions on $\mathrm{Ca}^{2+}$ homoeostasis. Bauassida et $\mathrm{al}^{13}$ showed that the $\mathrm{Ca}^{2+}$ concentration during the 7th and 21st minutes and at the end of high intensity exercise had decreased significantly compared with the preexercise values in two exercise protocols in physically active men. A significant decrease in $\mathrm{Ca}^{2+}$ and significant increase in parathyroid hormone have also been observed after moderate endurance exercise in young women. ${ }^{14}$ Ashizawa et $a^{15}$ found that urinary $\mathrm{Ca}^{2+}$ excretion significantly increased on the day of a single bout of resistance exercise in untrained young men. ${ }^{15}$ Parathyroid hormone and urinary excretion of $\mathrm{Ca}^{2+}$ seem to be two major factors in $\mathrm{Ca}^{2+}$ homoeostasis during and at the end of training.

\section{CONCLUSION}

Our results show that one standard 90 minute training session has the middle term effects of exercise on the regularly trained footballer. Blood viscosity tends to decrease after this type of training due to a reduction in red blood cell volume and packed cell volume. This may be a protective measure against the high shear rate conditions that occur at the end of a day's standard training. At the end of the football season, an increase in blood lactate concentration does not have an adverse effect on blood viscosity because a protective mechanism develops with regular training throughout the season. 


\section{What is already known on this topic}

Whole blood viscosity and plasma viscosity increase in response to a variety of exercise protocols.

\section{What this study adds}

In highly trained footballers, the increase in blood lactate at the end of a 90 minute training session (middle term effect) does not have the usual adverse effect on blood viscosity because of protective mechanisms that develop with regular training.

\section{ACKNOWLEDGEMENTS}

We thank Mustafa Taser, coach of the football team, for the organisation of standard training and the selection of the footballers.

\section{Authors' affiliations}

Y Karakoc, H Duzova, A Polat, M H Emre, Department of Physiology, Faculty of Medicine, Inonu University, Malatya, Turkey

I Arabaci, Undergraduate student, Faculty of Medicine, Inonu University

Competing interests: none declared

\section{REFERENCES}

1 Brun JF. Exercise hemorheology as a three acts play with metabolic actors: is it of clinical relevance. Clin Hemorheol Microcirc 2002;26:155-74.

2 Brun JF. Belhabas H, Granat MCh, et al. Postexercise red cell aggregation is negatively correlated with blood lactate rate of disappearance. Clin Hemorheol Microcirc 2002;26:231-9.

3 Convertino VA. Fluid shifts and hydration state: effects of long-term exercise. Can J Sport Sci 1987; 12(suppl 1):136-9.

4 Davis SN, Galassetti P, Wasserman DH, et al. Effects of gender on neuroendocrine and metabolic counterregulatory responces to exercise in normal man. J Clin Endocrinol Metab 2000;85:224-30.

5 Groussard C, Rannou-Bekono F, Machefer G, et al. Change in blood lipid peroxidation markers and antioxidants after a single sprint anaerobic exercise. Eur J Appl Physiol 2003;89:14-20.

6 Yan H, Kuroiwa A, Tanaka H, et al. Effect of moderate exercise on immune senescence in man. Eur J Appl Physiol 2001;86:105-11.

7 El-Sayed MS. Effects of exercise and training on blood rheology. Sport Med 1998:26:281-92

8 Nageswari K, Banerjee R, Gupte RV, et al. Effects of exercise on rheological and microcirculatory parameters. Clin Hemorheol Microcirc 2000;23:243-7.

9 Perez CJ, Nemet D, Mills PJ, et al. Effects of laboratory versus field exercise on leucocyte subsets and cell adhesion molecule expression in children. Eur J Appl Physiol 2001;86:34-9

10 Rebelo AN, Candeias JR, Fraga MM, et al. The impact of soccer training on the immune system. J Sports Med Phys Fitness 1998:38:258-61.

11 Bunn FH. Hematologic alterations. In: Wilson J, Braunwauld E, Isselbacher KJ, et al, eds. Harrison's principles of internal medicine.12th ed. New York: McGraw Hill, 1991; 1:344-62.

12 Abernethy B, Kippers V, Mackinnon LT, et al. The biophysical foundations of human movement. Champaign, IL: Human Kinetics Publishers, 1997:190-1.

13 Bauassida A, Zalleg D, Zaouali Ajina M, et al. Parathyroid hormone concentrations during and after two periods of high intensity exercise with and without an intervening recovery period. Eur J Appl Physiol 2003;88:339-44.

14 Thorsen K, Kristoffersson A, Hultdin J, et al. Effects of moderate endurance exercise on calcium, parathyroid hormone, and markers of bone metabolism in young women. Calcif Tissue Int 1997;60:16-20.

15 Ashizawa N, Ouchi G, Fujimura R, et al. Effects of single bout of resistance exercise on calcium and bone metabolism in untrained young males. Calcif Tissue Int 1998:62:104-8. 